\title{
"Traficos fronterizos". Introducción a la problemática de la adopción de niños en Misiones, Argentina*
}

\author{
Mónica Tarducci**
}

\begin{abstract}
Resumo
Misiones, la provincia del nordeste argentino, ha sido historicamente el "paraíso de las adopciones" por la rapidez y la facilidad legal de la guarda pre-adoptiva, la oferta numerosa de niños y su apreciado color de piel, propio de la poblacion del este de Europa que colonizó el territorio. En los últimos años se habla de "venta de niños" a familias extranjeras, lo que constituiría tráfico de personas ya que la ley impide la adopción internacional. Analizaremos en el articulo las consecuencias que esas denuncias tienen en la vida de las personas que viven allí.
\end{abstract}

Palavras-chave: Adopción, Adopción Transnacional, Tráfico de Personas.

\footnotetext{
* Recebido para publicação em maio de 2006, aprovado em junho de 2006.

** Universidad Nacional de San Martín-Universidad Nacional de Buenos Aires. tarducci@fibertel.com.ar
} 
"Traficos fronterizos"

"Border Traffic".

An Introduction to Children Adoption in Misiones, Argentina

\begin{abstract}
Misiones, in the Northestern Argentinian border, is "the paradise of adoptions", because there it's very easy the adoption proceedings, there are many poor children and, the flow of Central European immigrants means that these children are white. Mass Media and NGO's report "children for sale" to foreigner families. International Adoption is prohibited in Argentine. This article analyze the consequences of these reports in the lives of people of Misiones.
\end{abstract}

Key Words: Adoption, Transnational Adoption, Trafficking in Persons. 
Mónica Tarducci

\section{Las cuestiones legales}

Argentina tuvo su primera ley de Adopción en el año 1948, la número 13.252, derogada por la 19.134 del 29 de julio de 1971 , que la reemplaza.

La Convención Internacional sobre los Derechos del Niño (CIDN), adoptada por la Asamblea General de la Naciones Unidas el 20 de enero de 1989, fue incorporada con la reforma del año 1994 a la Constitución Nacional. De esta manera, la ley 23.849 otorga jerarquía constitucional a los tratados de Derechos Humanos como la Convención. Sin embargo, esta ley, sancionada en 1990 hace reserva del artículo 21 de la CIDN, en sus incisos b), c), d) y e)

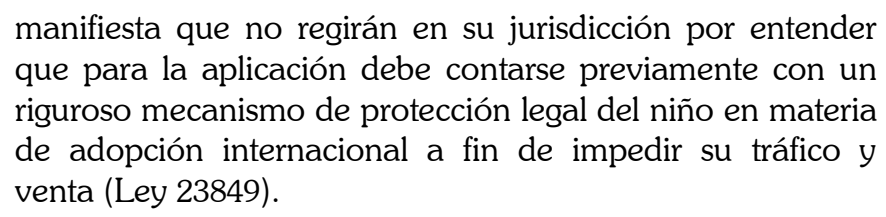

manifiesta que no regirán en su jurisdicción por entender que para la aplicación debe contarse previamente con un riguroso mecanismo de protección legal del niño en materia de adopción internacional a fin de impedir su tráfico y venta (Ley 23849).

¿Qué es lo que expresa el articulo 21 de la Convención? Expresa que los estados reconocerán que la adopción en otro país puede ser considerada como otro medio de cuidar del niño, en el caso de que éste no pueda ser colocado en un hogar de guarda o entregado a una familia adoptiva o no pueda ser atendido de manera adecuada en el país de origen. Por su parte, la ley 24779, del año 1997, que se incorpora al Código Civil, requiere que el adoptante tenga residencia permanente en el país por un período no menor de cinco años anteriores al pedido de guarda, debiendo esta circunstancia ser acreditada en forma fehaciente $e$ indubitable. Esta cláusula en la práctica, impide la adopción internacional en la Argentina.

En diciembre de 2003, el Congreso de la Nación sancionó la ley 25.854 que crea el Registro Único de Aspirantes con fines Adoptivos, que había sido previsto en la ley de adopción mencionada anteriormente. El propósito explícito de este registro 
"Traficos fronterizos"

es evitar que las personas que quieren adoptar se inscriban en varios registros para acceder a la adopción de un menor y brindar a los jueces y organismos oficiales a cargo de estas tareas un listado centralizado y seguro de aspirantes. De ahora en mas, una sola inscripción vale para todo el país y se estimula a que todas las provincias se sumen al Registro. Adhesión que sólo la Ciudad Autónoma de Buenos Aires ha realizado hasta ahora.

Sin embargo, lo que la prensa argentina presentó como una medida importantísima para el bienestar de los niños y niñas, recibió críticas de los especialistas cuando el decreto $N^{\circ} 383 / 2005$ reglamentó la ley $25.854{ }^{1}$

El problema fue su articulo $9^{\circ}$ :

A efectos del cómputo del plazo de residencia exigido por el articulo $5^{\circ}$ de la ley 25.854, podrán sumarse distintos períodos en los que los aspirantes hayan residido efectivamente en el país. ${ }^{2}$

De esta manera se contradecía el espíritu de la ley vigente y se abría la posibilidad de adoptar a extranjeros con residencia temporaria en Argentina. Fue tal el escándalo, que el Estado remedió la situación subsanando esa y otras objeciones. Volveremos sobre cuestión mas adelante.

\section{¿Por qué Misiones?}

Misiones esta ubicada en el Nordeste de la República Argentina y es apreciada a nivel mundial por el potencial turístico de sus famosas Cataratas del Iguazú. La casi totalidad de sus límites son ríos: el Iguazú al norte; el Paraná al oeste; al este el Uruguay y Peperíguazu y al sur el Chirimay.

\footnotetext{
${ }^{1}$ Fue muy importante la polémica desatada en el diario Pagina 12, entre quienes defendían la ley y Eva Giberti, conocida especialista en temas de adopción. En especial, notas de los días 31 de mayo y 28 de junio de 2005.

${ }^{2}$ http//infoleg.mecon.gov.ar/txnorma/105873.htm
} 
Pero lo que la hace mas especial aún es que el $80 \%$ de sus límites son internacionales: norte y este Brasil y al oeste Paraguay. Con una superficie de $29.801 \mathrm{~km}^{2}$, su territorio es una zona conocida como de "triple frontera", eje de circulación de mercancías y personas.

Por otra parte, tiene una peculiaridad que es especialmente importante para nuestro análisis: en primer lugar, la provincia recibió gran cantidad de inmigrantes polacos y ucranianos entre los años 1883 y 1927; provenientes del Imperio AustroHúngaro e inmigración alemana entre los años 1920 y 1946. Con posterioridad arribaron rusos, ucranianos, suecos, suizos, españoles, italianos, árabes, franceses, coreanos y vietnamitas, además del flujo incesante de inmigrantes de Brasil y Paraguay.

En segundo lugar, existe una práctica, mas habitual que en otras regiones del país, que es la "entrega" de hijos de los campesinos mas pobres a los colonos más solventes para que los "críen". Según una defensora de menores de la ciudad de Oberá

por cuanto sus familias biológicas no los podían mantener, y los colonos se iban quedando solos por la migración de los dos o tres hijos a ciudades para estudiar, o por el casamiento y consecuente alejamiento del hogar paterno, sea para tomar posesión de otras parcelas fiscales desocupadas o para ir en busca de condiciones laborales más ventajosas en las grandes ciudades o en las pequeñas en formación. ${ }^{3}$

Según la totalidad de los informantes locales, esta práctica fue constituyéndose en una institución en la provincia. Muchas veces esos niños y niñas fueron anotados como propios por las familias que los criaron. Otras, las madres los entregaron en preadopción, con la intervención de la Justicia. Es lo que se llama entrega directa, permitida por la ley. $\mathrm{O}$ sea que las madres no entregan sus hijos a los órganos judiciales, para que sean éstos los

3 Comunicación personal, Oberá, Misiones, setiembre de 2005. 
"Traficos fronterizos"

encargados de buscarle padres a los niños, porque no confían en los jueces, ni en las instituciones públicas; quieren, más bien, asegurarse que el matrimonio o la persona - que se lleve a su hijo, se lo lleve lejos para vivir una mejor vida -, sin perjuicio del contacto permanente con los guardadores por teléfono o por carta, vigilando el crecimiento de su hijo a través de fotografías o viéndolo personalmente en las audiencias.

Misiones se convirtió así en el paraíso de las adopciones. Creo que toda persona que viva en el país conoce casos de mujeres de Buenos Aires y otros lugares que viajaron a esta provincia y volvieron con su bebé. Con todo legalmente en orden. Otro es el caso de anotar como propio un hijo ajeno, práctica que, precisamente por su propia ilegalidad al margen de cualquier proceso judicial, es mas difícil de detectar.

Entonces, en Misiones se aúnan la rapidez y facilidad legal de la guarda pre-adoptiva directa, la oferta numerosa de niños y su apreciado color de piel, propio de la población del este de Europa que colonizó la zona. ${ }^{4}$

A estas condiciones se le suman los índices de pobreza, que según datos del INDEC, para los menores de 18 años es de $65 \%$ y de $27,7 \%$ de indigentes.

Por otra parte Misiones es una de las provincias con mas alto índice de embarazo adolescente según la amplia investigación llevada a cabo por el Ministerio de Salud y el CEDES en 2004. ${ }^{5}$ Sin embargo, en nuestro trabajo de campo en Oberá, hemos podido comprobar que estas casi niñas no son las principales dadoras de niños en adopción. Lo habitual es que madres muy jóvenes que ya tienen más de cuatro hijos y ningún progenitor que se haga cargo de ellos, comiencen a dar sus hijos en adopción a cambio de comida, chapas para el rancho, ropa, etc.

${ }^{4}$ No olvidemos que hasta hace muy poco tiempo, los padres y madres adoptivos buscaban niños fenotipicamente semejantes a ellos.

${ }^{5}$ CEDES. El embarazo en la adolescencia. Diagnóstico para la reorientación de politicas y programas de salud. http://www.cedes.org/informacion/ci/publicaciones index.html 
Lo que desde los medios llaman "venta de niños" es todo el proceso de intermediación, es decir, los estudios de abogados, que hacen los trámites, preparan las "carpetas" con los informes que presentarán al juzgado y conectan a la mujer embarazada, o con el niño o niña recién nacido con los interesados en adoptar. Todo este proceso se realiza abiertamente para la adopción en Argentina, no (se supone) para la adopción por extranjeros, que es lo que estamos investigando.

\section{Asuntos sensibles}

Mas allá de que la investigación siga su curso, yo quisiera aprovechar este breve artículo para reflexionar o mejor dicho continuar una reflexión que venimos teniendo con colegas de España e Iberoamérica y que fue explícita en el Simposio sobre "Transnacionalización y género" del I Congreso Latinoamericano de Antropología, llevado a cabo en julio pasado en Rosario, Argentina. ${ }^{6}$ Se refiere a la incidencia que tienen sobre las políticas de estado, la investigación y lo que es mas importante, sobre la vida de las personas concretas, (en este caso las mujeres y los niños y las niñas) la imposición de agendas sobre temáticas específicas desde los centros de poder hacia las periferias. Estoy hablando de la problemática de la lucha contra "la trata de personas, en especial, mujeres y niños".

Argentina ratificó por ley 25.632, en el año 2002 la Convención de las Naciones Unidas contra el Crimen Transnacional Organizado y su Protocolo para prevenir, reprimir y sancionar la Trata de Personas, especialmente mujeres y niños, conocido como Protocolo de Palermo. Esto obliga al estado nacional a realizar acciones en áreas de legislación, prevención, protección y asistencia a las víctimas, acuerdos de cooperación entre organismos estatales y organizaciones no-gubernamentales,

${ }^{6}$ Entre los días 11 y 15 de julio de 2005. Coordinado por Adriana Piscitelli y Mónica Tarducci. 
"Traficos fronterizos"

investigación, persecución penal del delito y coordinación y cooperación con otros países.

¿Qué tiene de malo todo esto? Los organismos internaciones hacen suyas las inquietudes de las feministas que nos hemos opuesto históricamente a todas las formas de trato injusto que afecte la vida de las mujeres y de sus hijos e hijas. Pero algunas pensamos que mas que hechas para el bienestar de las mujeres son leyes anti-inmigración que favorecen la represión estatal en su afán de proteger sus fronteras. ${ }^{7}$

Lo que si me interesa subrayar, además de las cuestiones que tienen que ver con el llamado "tráfico de niños" es que los primeros instrumentos internacionales contra la trata de personas, suscitaron la preocupación de algunas organizaciones nogubernamentales acerca de la debilidad en cuanto al respeto de los Derechos Humanos de las personas que decía proteger. Cito textual:

el ímpetu para desarrollar este nuevo instrumento internacional de los gobiernos para crear un instrumento para combatir el enorme crecimiento del crimen organizado transnacional. Por lo tanto, los redactores crearon un instrumento de aplicación fuerte de la ley con un lenguaje relativamente débil sobre las protecciones de los derechos humanos y la asistencia de las personas tratadas.

Previene además, sobre un enfoque que trata a las víctimas, en su mayoría inmigrantes, como criminales. ${ }^{8}$

En el caso específico de los niños el documento llama la atención sobre las condiciones sociales que hacen posible la trata

${ }^{7}$ El caso de la Trata de Mujeres es el mas paradigmático y el diálogo permanente con las colegas que investigan temas relacionados con la prostitución en contextos transnacionales lo afirma.

8 Global Rights. Partner for Justice. Guía anotada del Protocolo Completo de la ONU contra la Trata de Personas. 2005 
$e$ insiste en que son necesarias medidas especiales que tengan cuenta su situación.

Las mismas ONG's que crecieron al amparo de la prioridad temática de la Trata, comienzan a ver las consecuencias no queridas de la aplicación de las supuestas medidas para combatirla.

La Alianza Global contra la Trata de Mujeres, editó en 2004, un Manual de Derechos Humanos y Trata de Personas, que expresa textualmente: "Los Derechos Humanos de las personas víctimas de la trata son violados ampliamente por parte de los gobiernos".(67)

Pero ésto no es lo que se conoce mas ampliamente. Sobre lo que se insiste, mezclando nacionalismo y sensiblería, es sobre la magnitud de la trata y se dan cifras sobredimensionadas, se crean organismos nacionales, regionales e internacionales mientras, es obvio decirlo, no se atacan las causas ni se protege a las víctimas.

\section{Volviendo a Misiones}

Cuando se lee "adopción internacional en Misiones", o "tráfico de niños en el Noroeste del país", con subtítulos prometedores, a partir de las primeras líneas sobreviene la desilusión, de habla de la amplitud del fenómeno, del "terrible flagelo", sin un dato seguro, para terminar dando ejemplos de otros países, como Brasil o Paraguay.

Ejemplo de lo que decimos es el documento publicado en 2004, por el Consejo Nacional de Niñez, Adolescencia y Familia, organismo federal que depende de la presidencia de la Nación Argentina, denominado "Investigación sobre tráfico de niños, niñas y adolescentes con fines de explotación sexual, pornografía infantil en Internet y marcos normativos". Utiliza como fuentes de sus contundentes afirmaciones sólo dos investigaciones realizadas por especialistas académicas, ambas sobre prostitución infantil, de cuya seriedad no dudamos. Las demás fuentes son diarios y periódicos, datos del Departamento de Estado de los Estados 
"Traficos fronterizos"

Unidos, y la opinión de "expertos", o sea informantes calificados, cuyas declaraciones no están avaladas por ninguna investigación concreta. Claramente no existen datos como en el mismo documento se reconoce. O suceden cosas insólitas, se habla de tráfico niños para el comercio de órganos y se concluye con que la antropóloga Nancy Scheper-Hughes estuvo dos veces en el país y afirmó rotundamente que no existe tal cosa en Argentina.

Dejaremos de lado lo expresado en el documento acerca de la pornografía y prostitución infantil, así como la realidad constatable del trabajo realizado por niñas y niños a la vista de todo el mundo. Además de no ser el motivo de esta exposición, creemos que no son fenómenos comparables respecto de su magnitud, con la adopción internacional.

En todo caso, debería haberse titulado "trata" y no tráfico. ${ }^{9}$ $\mathrm{O}$ especificar cuando se da una u otra situación, dado que esa diferencia es la que efectúan los mismos organismos que crearon y popularizaron esta terminología.

Leemos en la página 26 del documento acerca de la magnitud del tráfico de bebes, en realidad, de la compra de bebes en la zona de la Triple Frontera y las fuentes citadas son un libro sensacionalista del periodista Alfredo Silleta, conocido y repudiado en Argentina por su oportunismo y falta de seriedad y un articulo periodístico de un diario nacional. Se llega a un grado de imprecisión y fabulación alarmantes, por ejemplo afirmar que los compradores de niños vienen de Paraguay, Europa y China (i!!!).

Cuando se reglamentó la ley del registro único de aspirantes a la adopción, con el polémico artículo a que hacíamos referencia, se apeló de tal manera a estas ligeras aseveraciones que parecía que Argentina sufría una exportación de niños semejante a Rumania (notable por su cantidad e las irregularidades encontradas). No sólo se polemizó en diarios y revistas de gran

9 Según el Curso sobre el tema dictado por la OIM (Organización Internacional de Migraciones) en Buenos Aires, en 2005: Trata implica explotación dentro o fuera de las fronteras nacionales, trafico siempre es cruce irregular de fronteras, sea para el fin que sea. 
circulación, se apeló a Internet y se crearon listas de padres y madres adoptantes autoconvocados ante el peligro de la "exportación de niños".

Yo no estoy diciendo que la trata de personas, incluida la de niños no exista, me estoy preguntando acerca de quién hace prioritario un tema y por qué se lo sobredimensiona. ¿Qué rol cumplen las agencias internacionales que los colocan en la agenda sólo cuando afectan a los países hegemónicos, en especial a Estados Unidos.

A partir de esa prioridad emanan directivas para los países periféricos. Esas directivas provocan cambios judiciales $y$ legislativos, pero lo que tenemos que pensar es de qué manera afectan la vida de las personas que sufren la trata y el tráfico y cómo nos situamos como cientistas sociales ante estas pseudoverdades que se repiten como dogmas de fé mas que como resultados de investigaciones imparciales.

Tampoco estoy diciendo que el tráfico de niños no exista en la Triple Frontera (Argentina-Brasil-Paraguay), donde circulan mercancías, armas, drogas y tiene lugar todo tipo de comercio ilegal. ¿̇por qué no personas? ¿̇por qué no niños? ${ }^{10}$

El problema es que se asume que es así, pero ni los comandantes de gendarmería lo aseguran, a pesar de que el Ministerio de Justicia les pide informes y ellos informan lo que se espera que informen.

Lo que si ha cambiado es el control fronterizo, el maltrato hacia la mujer que da un niño en adopción, la lentitud en resolver las adopciones y particularidades territoriales como las llamadas "acordadas" de los Tribunales Superiores de las provincias fronterizas de Misiones y Corrientes que establecen que un menor de un año de edad debe tener autorización judicial para salir de

\footnotetext{
${ }^{10}$ De hecho nuestra investigación se inscribe en lo que se ha dado en llamar "Estudios Transnacionales" y ubicamos a la adopción como un fenómeno enormemente facilitado por la globalización.
} 
"Traficos fronterizos"

sus territorios con otras personas que no sean sus padres o madres.

También, a partir del 1 de agosto de este año la Dirección Nacional de Migraciones, por disposición No 31100/05 establece que cada vez que un menor de 6 años abandone el territorio nacional necesitará de un permiso donde se especificará el destino, con quien viaja, para qué fines y eso quedará asentado en un control migratorio.

Entonces, lo que se provoca, es la profundización de medidas represivas, mayor brutalidad de quienes controlan las fronteras, miedo de los jueces a que se los trate de cómplices del tráfico, lo que redunda en la poca disponibilidad para dar niños en adopción y la discriminación de las mujeres que dan sus bebes en adopción, que son acusadas hasta por sus mismos parientes y amigos, de "vender sus hijos".

Este sensacionalismo evita centrarse en el tema de la adopción en sí, que en nuestra investigación pasa por múltiples niveles de análisis: lo local y lo global, clase, género y factores étnicos entre otros.

Nos interesa cómo se produce ese tránsito entre familias pobres y "mal constituídas" hacia familias "normales" de clases de mayor solvencia económica y hasta de países más poderosos. De qué manera las determinaciones de género hacen explícita una maternidad mala (la de las mujeres que entregan sus hijos en adopción) y una buena, la de aquellas que quieren a toda costa ser madres. Comprobar si realmente se prefieren las niñas a los varones, como nos lo decían algunos informantes en el trabajo de campo.

Creemos que la adopción transnacional es un área fascinante para la antropología feminista porque pone en discusión temas que siempre nos han interesado: el parentesco, la construcción social de la maternidad, los estudios de frontera y otros, con el poderoso marco actual de la globalización. Contexto éste que moviliza fuerzas de tal magnitud que nos obliga a ser cautas, honestas y hacer honor a los principios políticos de la 
Mónica Tarducci

antropología tal cual la entendemos quienes estamos comprometidas con la emancipación de las mujeres que no traiciones los principios fundamentales del trabajo intelectual. 